Journal of Critical Race Inquiry

Volume 7, Number 1 (2020) pp. 84-92

\title{
Decolonizing Kink: Nishinaabeg stories as critical engagements with power*
}

\author{
Adria Kurchina-Tyson \\ Department of Gender Studies, Queen's University \\ *An earlier version of this paper was presented at the Reimagining Kinship, Gender, and \\ Sexuality in Indigenous Communities Colloquium held in Kingston, Ontario at Queen's \\ University in January 2019.
}

\begin{abstract}
The purpose of this paper is to address interpretations of Nishinaabeg epistemologies and pedagogies that replicate essentialist modes of storytelling and governance. This paper elaborates on Anishinaabek theories of consent and consent-based governance systems by drawing upon our stories and storytelling practices. Presenting Anishinaabeg storytelling practices as critically reflexive engagements with power, this paper demonstrates the untranslatability of Nishinaabeg methods of governance to colonial contexts of systemic violence. The intention of this work is to reveal how Nishinaabeg relationship governance practices are fundamentally oriented to consent, sustainability, and collective and/or mutual/reciprocal validation.
\end{abstract}

\section{Introduction}

Kinkphobia is colonial. It is a product of colonial rape culture. This paper explores kinky ways of relating as a method of decolonization, and particularly as an investment in the resurgence of Nishinaabek consent cultures. I approach kinship and intimate relationships using principles of Anishinaabeg governance and storytelling, in ways that are critically consent-based, non-essentialist, and anti-colonial.

For the purpose of this paper, my definition of "kink" is very flexible. While the term "kink" is typically used to describe specific sex acts and relationship dynamics that are 
considered taboo (which of course varies according to context), I use "kink" here to describe a method, or ethics of relating, that applies critical analyses of power to practices of desire and consent-based validation. I argue that the necessity to explicitly address consent arises out of a context in which it is generally absent. While this may read as a paradox, what I mean to express is that consent should exist as a phenomenon or inherent cultural practice, rather than a circumstantial or standardized protocol. Consent can and has existed as such long before the violently imposed presence of settler colonialism (Simpson, 2017, p. 182). In contemporary settler colonial contexts, consent is understood as a measurable, identifiable, or quantifiable thing, which must be actively regulated against the grain of its own systems of non-consent. Explicit conversations about consent are thus necessitated by its persistent violation.

Reactionary responses to rape culture (such as the circulation of standardized definitions of consent) take for granted its naturalness by infantilizing agents of sexual and other kinds of violence. In other words, they position sexual violence as something merely done out of ignorance and/or immaturity. Given the failure of such logics to address violence as a system - or to define violence in terms of non-consent itself — there also exists a reactionary conflation between kink and sexual violence. This creates a prescriptively "vanilla" culture - one that normalizes "gentle" or non-aggressive sex, while stigmatizing kink - which disregards consent altogether, as well as the diversity of desires and subjectivities.

These prescriptive logics tend to leak into some conversations about Indigenous traditional governance, but only when our systems of governance are presented as oppositional to - rather than fundamentally different from-colonial power structures. We rightfully insist that our governance practices are traditionally consent-based and consentoriented, but iterations and interpretations of this must be careful and critical, since traditional teachings cannot be applied in a prescriptive manner, or be repurposed without an account for such a profound change in context.

\section{Nishinaabe Foundations of Consent}

One of the ways in which Anishnaabeg consent culture manifests itself is through storytelling. While storytelling is a Nishinaabeg method of governance, our stories are not to be confused with prescriptive practices of storytelling, such as parables or "legends." Our storytelling practices provoke critical thought and reflexivity for the purpose of navigating inevitably diverse relationships and relationship dynamics in inevitably diverse ways. I think 
of our stories like porn, and otherwise as poetry. Our stories do not have the sole or even necessary purpose of establishing moral structure. Instead, they nurture reflexive, imaginative processes of relating, in ways that sustain various relational ecosystems, and enable mutual validation as a method of reciprocity.

As an articulation of Indigenous governance preceding colonial understandings of consent, in which consent is a thing to be gained, Leanne Betasamosake Simpson describes Anishinaabeg governance practices as generating consent (Simpson, 2017, p. 161-165). Although the English language is limited in articulating these conceptual nuances, Simpson's theoretical shift from gaining to generating points to an altogether different set of relations, in which reciprocity is inherent, and where power is not structured but collectively understood as complex, fluid, and performative, and relationships are approached accordingly.

When interpreting traditional teachings and re-tellings of stories, we must account for their change in context. Failing to do so risks distorting and oversimplifying Nishinaabeg storytelling as a pedagogy, by reducing its reflexive processes of meaning-making to the purpose of a fable (and by inference, moral policing) (Simpson, 2017, p. 57).

It is common for Nishinaabeg theorists to illustrate principles and practices of traditional governance using stories about interspecies - sometimes human-animalrelationships (Cajete, 2000, p. 149-176; Simpson, 2011, p. 103-106). These theorists make it clear that the essentialist human over "nature" hierarchy imposed by the colonizers is one which, for Anishinaabek and other Indigenous nations, does not exist as an ideology. Nonetheless, in the absence of essentialist hierarchies we can see that hunting, for example, is a sometimes unavoidable practice of exercising power in one way or another. It is clear in Nishinaabeg storytelling that power dynamics between humans and hunted animals - in which "we eat our relatives," to borrow the words of Kim TallBear - are approached accordingly in self-reflexive ways (Simpson, 2011, p. 111-113; Tallbear, 2016, p. 15).

For example, Simpson details a hunting story, wherein a deer takes pity on the hunter and their family, and gives them their life (Simpson, 2011, p. 111). An essentialist reading of this teaching would assume that the purpose of this story is to place the deer in a position of power over the hunter. However, contrary to establishing and enforcing an essentialized power structure, this story is known among Nishinaabe people to be one of many stories. And these stories are often contradictory from an essentialist perspective, because none are attempting to establish a universal truth or moral structure (Simpson, 2017, p. 122). To make this about consent, this particular story, among others, reveals the performative nature of power and its fluidity. At its most structured or strategic, this story highlights the humbling co-dependency of sometimes unequal agents for validation and survival. Melissa K. Nelson 
notes a similar so-called reversal in the Nishinaabeg story of beavers, who exploit human hunters for their gifts (which hunters offer whenever a beaver is killed) (Nelson, 2017, p. 244). The principle of reciprocity within Nishinaabe knowledge systems does not deny that exchanges of power are implicated in relations, nor do they intend to prescribe certain power dynamics. Instead, these playful subversions take for granted that power is performative - that this exchange can be imagined and done in many ways, while sustainability remains of unquestionable priority. The performativity of power is humbling. In a practical way, it allows for hunting to be a sexy and validating experience for many different types of folks - perhaps for everyone involved - and this kind of role play is inconsequential to the common-sense principles of consent and reciprocity.

\section{Nishinaabe Foundations of Playfulness}

Also flexible in purpose are Nanaboozhoo or "trickster" stories in Anishinaabek storytelling. Nanaboozhoo is known as a shape-shifter. Nanaboozhoo behaves differently, their desires depicted differently, within each dynamic, although not necessarily according to each dynamic. Nanaboozhoo is sometimes gentle and sometimes sadistic in their interactions with the land, water, and other relatives. Within colonial epistemologies of structured morality-or the regulation of morality through non-consent, and policing — stories of Nanaboozhoo's cheeky, hedonistic, and sometimes sadistic tendencies are often taken up as cautionary tales for how not to relate.

The problem with presenting Nanaboozhoo stories in opposition to settler epistemologies, however-drawing false parallels between structures of systemic violence and anecdotes of interpersonal conflict or imbalance - is that it inevitably distorts the purpose and potential of these stories for critical relational engagement. So-called trickster stories do not exist for the purpose of correcting or accommodating colonial culture (even while Indigenous people survive these teachings within colonial contexts with remarkable resiliency). Instead, they are carried through ways of knowing and relating that are untranslatable to colonial understandings and structures of relationships. Furthermore, these distortions of Nanaboozhoo stories tend to suggest that systemic oppression is a consequence of the absence of structure and discipline. This naturalizes not only the systemic violence that is framed as consequential to a lack of control, but also the perceived need for the control that rises as a reactionary response to it. Unlike colonial parables or fables, Nanaboozhoo stories - and Nishinaabeg storytelling practices in general - take for granted the fluidity and 
complexity of relationship dynamics within various contexts (Simpson, 2017, p. 57). They do not seek to establish fixed relational structures, nor do they strive for hegemony.

Simpson subverts the aforementioned moralization of Nanaboozhoo in her re-tellings of trickster stories. In The Gift is in the Making, Simpson tells a story about Nanaboozhoo riding with the geese down south for the winter (Simpson, 2013, p. 53-58). Returning home from the trip, Nanaboozhoo disobeys the rules, and the geese drop them from the sky prematurely, as promised. Rather than framing this story around order and discipline, Simpson ends the story with Nanaboozhoo landing in a muddy lake, and simply remarking on how muddy the lake is (Simpson, 2013, p. 58). Even the so-called disobedience of Nanaboozhoo is not attributed any value beyond practical (and consensually negotiated) outcomes. Prior to their flight, the geese simply let Nanaboozhoo know that if they look down or speak in-flight, they will drop them. Nanaboozhoo makes an informed decision to do so, which does not necessitate any kind of intervention beyond the forewarned consequences.

Another story from this collection, which I read as consent-oriented and even more easily as kinky, is the story about wiigwaas and shiingwaak (the birch tree and the pine tree) (Simpson, 2013, p. 30-32). In this story, wiigwaas, the birch tree, has an inflated ego one day, and is swaying side to side boasting about how beautiful they are and how smooth their skin is - until shiingwaak, annoyed, joins them in swaying until their needles whip wiigwaas, leaving scratches in their bark. The way the story is told here, an inflated ego alone does not warrant punishment, although shiingwaak's irritation and its outcome are both validated. This story ends with wiigwaas wearing the scars they've endured proudly-making the narrative body-positive as well as self-love affirming, rather than a story of humiliation, shame, and punishment. This story is playful, and can be told in many ways. I like to think of wiigwaas as a little exhibitionist, whom shiingwaak flogs when they get bratty.

In Simpson's narration of a Nishinaabeg creation story with Nanabush, there is very explicit discussion of relationship reflexivity within her pedagogy. Nanabush walks the earth first alone, and then with a companion, Ma'iingan. Simpson states plainly that "the journey changes with a companion" (Simpson, 2017, p. 57-58). Rather than modeling a monolithic set of relations, the changing dynamics that Nanabush experiences through changes in relational contexts demand the use of negotiative practices of meaning-making. 


\section{Complicating Power in Indigenous Epistemologies}

This negotiative method of meaning-making and relating urges us to reconsider the concept of "roles" within traditional kinship and governance systems. Queer Indigenous people persistently challenge the gendering of so-called roles within traditional governance systems and kinship models (Wesley, 2015, p. 5). Indeed, there is no reason to assume that prior to colonization, roles - divisions of labour, etc. - would be determined by gender or even "sex." Moreover, perhaps attacks on our governance systems include not only the conversion of "roles" into "gender roles" but also the construction of roles as stagnant and pre-determined in the first place.

Many Indigenous epistemologies conceptualize gender in terms of complementarity and interdependence. This absence of hierarchy can also be applied to performative positions of power. Indeed, colonial ideas of roles are structured on essentialist binary hierarchies that devalue at once femininity and submission.

In their collaborative piece, "Top or Bottom: How do we desire?," Billy Ray Belcourt, Kay Gabriel, and George Dust address the intersecting hierarchies implicated in the colonial dom/sub binary. The discussion begins by addressing the commonly invoked crisis of a "top shortage" within queer scenes, which tends to replicate colonial hierarchies by invoking racialized tropes of sexuality. Kay Gabriel explains how the idea of a shortage of tops reveals the value hierarchy on which tops and bottoms are placed - in particular the devaluation of submission and its false association with passivity rather than sexual agency. In response to this idea of a top shortage, Billy Ray Belcourt asks "if there is a top shortage, is there also a 'bottom surplus'?"

I like to think about Belcourt's playful invocation of a "bottom surplus" in relationship to a conversation I had with my mishomis once about wasps, hornets, and bees. In a likely attempt to defend capitalism, he told me once that he had been thinking about the governance systems of "wasps, hornets, and bees" as "technically speaking, a matriarchal capitalism" (Kurchina, 2017). Preceding that conversation I had also been thinking about wasps, but in a different way - specifically about wasps in relationship to humans, as dominant tricksters.

My mishomis was not attempting to distinguish consent-based norms in his initial thesis about stinger beings. Indeed, his intention was to apply the governance systems of stingers to humans prescriptively in order to justify that which already exists under the colonial regime. Of course, this application makes no sense within many Indigenous epistemologies, in which necessary considerations of context are made (Cordova, 2004, p. 2733). However, by inadvertently de-centering humans in his analysis, what he offered was an 
account of how these governance systems - these systems of apparent unevenness or imbalance-work for these bee-ings indefinitely. I proceeded to argue of course that the governance systems of wasps need not be applied to human relations. In the first place, capitalism is clearly unsustainable when practiced by human beings (Robinson, 1983).

Moreover, understanding these systems as so-called capitalism is very likely an oversimplified projection of contemporary colonial systems of non-consent which do not translate within these contexts. How can we read these relations in a way that doesn't presume and effectively naturalize non-consent? Should we attempt to read them at all, since it is impossible to understand how consent is generated from outside of that context? What if drones consent to dying, or die by choice, at the end of the season? Can we really assume, from outside of that relational context, that drones are in inherently undesirable positions? What are the implications of assigning value to the seemingly submissive roles of the drones, or assuming those roles are submissive in the first place?

This brings me to the concept of balance. The concept of "balance" is commonly invoked by Indigenous traditionalists in defense of Indigenous systems of ethics and reciprocity. I argue that prescriptive applications of balance as a precept can be dangerous, in that they risk upholding colonial binaries and moral dichotomies that do not account for consent nor context. Within these binary logics of power, there clearly appears a so-called imbalance among wasps, hornets, and bees. However, within Indigenous frameworks, in which things like "anomaly" and "chaos" are deeply valued, such imbalances can exist within consensual and sustainable dynamics, likely among all living beings (Cajete, 2000, p. 16; Justice, 2010; Wesley, 2015, p. 30; Yazzie Burkhart, 2004, p. 25). As Cordova (2004, p. 29) says, "One should ask oneself whether the concepts of 'balance' and 'harmony' actually make sense when transferred over to a context in which the world is described as essentially chaotic. Where, in other words, and how, does the idea of 'balance' arise?"

Ideas of balance that are prescriptively vanilla not only take for granted structural binaries, but also assign value to various experiences (take the bees, for example) including pain, submission, and even death.

\section{Conclusion}

The rigid and prescriptive logics of roles and power within the colonial imaginary do not allow for the existence of infinitely diverse relationship networks, nor do they account for these sustainable imbalances that manifest in various local contexts. No single relational 
network will function sustainably when its structure is imposed or prescribed from outside of the local context in which consent can be generated. Perhaps a shift from protocols to principles within traditionalist thinking (the former being prescriptive and the latter more generative), can better foster resurgent ways of relating that are fundamentally consent-based. Within Anishinaabek governance, no stable or fixed power relation is assumed to suffice through changes in relations, desires, needs, time, and context. "'Theory," Simpson (2014, p. 7) states, "is generated and regenerated continually through embodied practice and within each family, community, and generation of people." Generating consent is not done through policing or moral structure in a Nishinaabe context. Anishinaabe storytelling practices generate consent not through the indoctrination of knowledge-knowledge of how to act based on each story - but primarily through the inherent knowledge itself that each story is a story, hence the famous Thomas King quote, "the truth about stories is that's all we are" (2003, p. 92).

\section{References}

Belcourt, B. R., Dust, G., \& Gabriel, K. (2018). Top or bottom: How do we desire? The New Inquiry. Retrieved from https://thenewinquiry.com/top-or-bottom-how-do-we-desire/

Cajete, G. (2000). Native science: Natural laws of interdependence. Santa Fe, NM: Clear Light Publishers.

Cordova, V.F (2004). Approaches to Native American philosophy. In A. Waters (Ed.), American Indian thought (pp. 27-33). Hoboken, NJ: Blackwell Publishing.

Justice, D. H. (2010). Notes toward a theory of anomaly. GLQ: A Journal of Lesbian and Gay Studies, 16(1-2), 207-242.

King, T. (2003). The truth about stories: A native narrative. CBC Massey Lectures. Toronto, ON: House of Anansi Press.

Kurchina, E. T. (2017, September 18). Wasps, hornets, and bees. (A. Kurchina-Tyson, Interviewer) [Phone call].

Nelson, M. K. (2017). Getting dirty: The Eco-Eroticism of women in Indigenous oral literatures. In Joanne Barker (Ed.), Critically sovereign: Indigenous gender, sexuality, and feminist studies (pp. 229-260). Durham, NC: Duke University Press.

Robinson, C. (1983). Black Marxism: The making of the Black radical tradition. Chapel Hill: University of North Carolina Press. 
Simpson, L. B. (2017). As we have always done: Indigenous freedom through radical resistance. Minneapolis: University of Minnesota Press.

Simpson, L. B. (2014). Land as pedagogy: Nishinaabeg intelligence and rebellious transformation. Decolonization: Indigeneity, Education \& Society, 3(3), 1-25.

Simpson, L. B. (2011). Dancing on our turtle's back: Stories of Nishanaabeg re-creation, resurgence, and a new emergence. Winnipeg, MB: Arbeiter Ring Publishing.

TallBear, Kim (2016). Disrupting settlement, sex, and nature. Hosted by the Future Imaginary Lecture Series. Concordia University. Retrieved from http://indigenousfutures.net/wpcontent/uploads/2016/10/Kim_TallBear.pdf

Wesley, D. (2015). Reimagining two-spirit community: Critically centering narratives of urban two-spirit youth (Unpublished master's thesis). Queen's University, Kingston, ON.

Yazzie Burkhart, B. (2004). What coyote and thales can teach us: An outline of American Indian epistemology. In A. Waters (Ed.), American Indian thought (pp. 15-27). Hoboken, NJ: Blackwell Publishing. 